\title{
032 EMBEDDING THE PRINCIPLES OF GSF IN PRIMARY CARE: USING AN AMBULANCE/OUT OF HOURS COMMUNICATION FORM AS A CATALYST FOR IMPROVED COMMUNICATION ACROSS THE END OF LIFE PATHWAY
}

Debbie Westwood, ${ }^{1}$ Claire Curtis, ${ }^{2}$ Felix Blaine, ${ }^{3}$ Kerry Bagshaw ${ }^{4}$ NHS Worcestershire, Worcester; ${ }^{2}$ Kemp Hospice, Kidderminster, ${ }^{3}$ Spring Gardens Medical Practice, Worcester; ${ }^{4}$ NHS Worcestershire, Worcester

10.1136/bmjspcare-2012-000196.32

Background A good communication pathway has been established through the development of an out of hours communication form, which is held at the new West Midlands Ambulance Service (WMAS) hub in Leamington spa. The information communicated on this form, primarily by GPs, enables WMAS to communicate with its crews regarding any advance care plans or special needs of patients on the palliative care register that they may be called to. The form is also sent to the out-of-hours primary care service (Harmoni) to be added to their special notes system.

Outcomes This information is often vital in enabling paramedics to make decisions on whether to transfer patients or to enable them to remain in their own home.

Results A preliminary study showed the cost saving in transportation to the acute trust and in acute trust admissions to be $£ 74000$ in the first six months of its introduction. A full year's evaluation is awaited and will be available shortly. In real terms this means that 25 patients were not conveyed to hospital, as a direct contribution of the register being in place and the contributions of those healthcare professionals who submitted the relevant DNAR/special notices regarding their patients. Further developments to this scheme are planned. As both WMAS and Harmoni use Adastra systems, an electronic template has been developed that will allow GPs to fill out one form that will communicate with both organisations. The plan is for this to be accessible by the acute trust, to further enhance communication about the patients' wishes at end of life. Two surgeries in Worcestershire have the electronic end of life special notes template and are currently piloting it. Work needs to begin with Adastra nationally to create interface between Harmoni Adastra and WMAS Adastra. 